Viši naučni saradnik dr Mirjana Andelković-Lukić, dipl. inž.

\section{EKOLOŠKI ASPEKTI PRIMENE PIRALENA}

UDC: $621.315 .615: 504.06$

Rezime:

Piralen se koristi kao rashladni fluid u električnim transformatorima visokog napona. Spada u najopasnije zagađivače čovekove okoline. U radu su prikazane njegove fizičko-hemijske karakteristike, postupci pri isticanju iz ambalaže ili transformatora usled požara, postupci dekontaminacije $i$ način gašenja požara na piralenu i piralenskim transformatorima.

Ključne reči: piralen, genotoksin, ulje za hlađenje, dekontaminacija, gašenje požara.

\title{
ECOLOGICAL ASPECT OF PYRALEN APPLICATION
}

Summary:

Pyralen is used as a cooling fluid in high voltage electrical transformers. It belongs to a group of the most dangerous polluters of the environment. In the article it is presented pyralen's physical and chemical characteristics, procedures of decontamination and procedures in cases of leaking of pyralen from package or transformers, as well as procedures of firefight on pyralen and pyralen transformers.

Key words: Pyralen, genotoxis, cooling oil, decontamination, firefight.

\section{Uvod}

Životna sredina je s napretkom nauke i tehnologije sve ugroženija. Nekontrolisano izlivanje zagađenih industrijskih voda $\mathrm{u}$ otvorene vodotokove izaziva dugoročno zagađenje i otežano snabdevanje stanovništva vodom. Velika emisija gasova i čađi iz dimnjaka termocentrala na ugalj, cementara, železara i drugih industrijskih grana u atmosferu, izaziva efekat staklene bašte, usled čega dolazi do povećanog zagrevanja zemljine atmosfere i promene klime i ugrožavanja života različitih životinjskih i biljnih vrsta, ali i samog čoveka.

Očuvanje životne sredine danas je jedan od najvažnijih zahteva koji se posta- vlja pred proizvođače različitih hemijskih proizvoda. Ovi zahtevi odnose se na smanjenje emisije otrovnih gasova (Protokol iz Kjota), prečišćavanje otpadnih voda koje se ispuštaju u otvorene vodotokove reke, na zbrinjavanje (skladištenje) određenih hemijskih međuprodukata $\mathrm{i}$ hemijskog otpada koji ne mogu biti prerađeni, kao i na njihovo uklanjanje mehaničkim i hemijskim putem ili termičkom razgradnjom. Većina proizvoda hemijske industrije su zagađivači okoline, među kojima posebno mesto zauzimaju raznovrsni sintetski materijali koji se nalaze u širokoj primeni: polietileni, polipropileni, polivinilhloridi, i druge vrste plastičnih materijala, koji se nekontrolisano izbacuju u vi- 
du otpada u okolinu i čija razgradnja $u$ prirodi traje dugi niz godina. U grupu zagađivača spadaju i razne vrste sintetskog ulja, među kojima je najpoznatije transformatorsko ulje, trgovačkog naziva ,piralen“. Transformatorska ulja koriste se za hlađenje električnih transformatora, ali se primenjuju i kao maziva u nekim specifičnim slučajevima zatvorenih sistema. Ova ulja su nerazgradiva i spadaju u izuzetno opasne zagađivače čovekove okoline. Prodiranjem u tlo trajno zagađuju zemljište i podzemne vode.

Njihovim sagorevanjem na otvorenom prostoru oslobađa se veliki broj otrovnih kancerogenih produkata. Gašenje požara izazvanih gorenjem piralena, povezano je s velikim rizikom od trovanja i zagađenja okoline. Piralen je veoma stabilno, nerazgradivo ulje. Njegovo efikasno uklanjanje vrši se razgradnjom, termičkim putem, u posebno projektovanim pećima s filtrima, kako ni jedan opasan produkat sagorevanja piralena ne bi izašao u okolinu. Kod nas ovakav termički način uništavanja piralena ne postoji, pa se zbog toga izvozi u druge zemlje (Francuska), gde se vrši njegova inače izuzetno skupa termička razgradnja. Evropska unija ima veoma stroge ekološke propise i, s obzirom na to da je piralen toksičan i kancerogen, njegovo korišćenje je trajno zabranjeno. Požari na piralenskim transformatorima vrlo su retki, tako da je iskustvo koje su naši vatrogasci stekli tokom gašenja požara na piralenskim transformatorima $u$ toku agresije NATO-a novo i za stručnjake iz EU. Posebna nepoznanica je uticaj produkata sagorevanja piralena na zdravlje stanovništva.
U radu su prikazane karakteristike $\mathrm{i}$ upotreba sintetičkih transformatorskih ulja, njihovo štetno delovanje na čoveka i njegovu okolinu, način zbrinjavanja ukoliko iscure u okolinu i postupak gašenja požara na zapaljenim piralenskim transformatorima.

\section{Karakteristike transformatorskih ulja i primena}

Hlađenje velikih transformatora, koji su u sastavu elektroenergetskih sistema, neophodno je za njihov bezbedan i ispravan rad. Za hlađenje se koriste transformatorska ulja (trafo-ulja) - prirodna i sintetička [1].

Prirodno transformatorsko ulje ili „obično trafo-ulje“ je laneno, kome su dodati aditivi - dielektrični stabilizatori, otrovne i genotoksične supstance. Ova trafo-ulja nisu trajna i svake godine moraju da se prerađuju, odnosno, suše, jer su veoma higroskopna i apsorbuju vlagu iz vazduha. Njihova periodična prerada je neophodna, ali skupa i obavlja se u posebnim postrojenjima službe elektroodržavanja. Zbog toga se primena ovih ulja u preduzećima elektroprenosa sve više izbegava.

Sintetička, odnosno trajna ulja za hlađenje, sipaju se u transformatore kada se oni formiraju i traju koliko i sam transformator, tako da je cena njihovog održavanja zanemarljiva. Sintetička trafo-ulja imaju više naziva (hlorovani bifenili, polihlorovani difenili, polihlorovani polifenili, arohlor 1254, askarel, solvotol) od kojih je najrasprostranjeniji i svakako najpoznatiji piralen ili polihlorovani bifenil (PHB). 
Strukturna formula polihlorovanih bifenila prikazana je na slici.

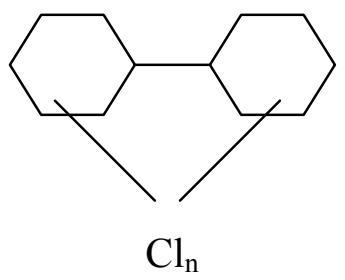

Strukturna formula polihlorovanih bifenila

Poznato je 46 izomera pentahlorbifenila. Za trajna transformatorska ulja najčešće se koristi pentahlorbifenil, bruto hemijske formule $\mathrm{C}_{12} \mathrm{H}_{5} \mathrm{Cl}_{5}$.

Pentahlorbifenil sa 54\% hlora je bledožuta, viskozna tečnost sa blagim mirisom ugljovodonika. Fizičko-hemijske osobine pentahlorbifenila su sledeće [1]: tivno);

- molekulska masa 326 (aproksima-

- temperatura ključanja $365-369^{\circ} \mathrm{C}$;

- temperatura topljenja $10^{\circ} \mathrm{C}$;

- temepratura paljenja $222^{\circ} \mathrm{C}$;

- rastvorljivost u vodi (na $20^{\circ} \mathrm{C}$ ) $<1 \mathrm{mg} / \mathrm{dm}^{3}$;

- zapreminska masa $1,505 \mathrm{~g} / \mathrm{cm}^{3}$.

Sintetička ulja su trajna, ne moraju periodično da se prerađuju, što predstavlja veliku prednost u odnosu na prirodna ulja. Međutim, sintetička trafo-ulja, piraleni, veoma su opasni zagađivači životne sredine i zbog toga se u Evropskoj uniji trajno eliminišu iz upotrebe [2] .

\section{Opasnost pri radu s piralenom}

Polihlorovani bifenili, koji spadaju u „mešavine“, genotoksične su hemikalije i, prema katalogizaciji Svetske zdravstvene organizacije pri UN, svrstane su u grupu 2A hemikalija sa verovatno kancerogenim delovanjem po ljude. Maksimalno dozvoljena količina (MDK) za piralen sa 54\% hlora je $0,5 \mathrm{mg} / \mathrm{m}^{3}$, za prosečno 8 sati. Prema američkim standardima (NIOSH), MDK je $0,001 \mathrm{mg} / \mathrm{m}^{3}$, za radni dan od najviše 10 sati i radnu nedelju od 40 sati. Piralen se smatra potencijalnim kancerogenom iz radne sredine (NIOSH 1992) [3].

Zbog dobre resorpcije preko kože, rad s ovim uljem je rizičan bez zaštitne opreme, čak i za navedene koncentracije MDK. Piralen spada u kumulativne otrove i ima sistemske efekte trovanja [3], koji se ispoljavaju u bliskoj ili daljoj budućnosti.

Velika opasnost u radu s piralenom je mogućnost nastajanja požara jačim zagrevanjem. U dodiru s plamenom piralen gori, usled čega nastaje čitava lepeza genotoksina koji se kondenzuju u čađi ili se jednostavno nalaze u dimu. Neki od nastalih genotoksina su: polihlorovani dibenzofurani; hlorovani benzo-para-dioksini; hlorovani fenoli; hlorovani naftaleni; ugljenmonoksid i hlorovodonik.

Sva jedinjenja nastala gorenjem piralena su otrovna i kancerogena. Pored navedenih jedinjenja, tokom gorenja piralena nastaje i znatna količina čađi, kao čvrst proizvod sagorevanja.

\section{Zaštita od kontaminacije piralenom}

Kontaminacija ljudi piralenom moguća je na nekoliko načina, udisanjem kontaminiranog vazduha, kontaktom $\mathrm{s}$ očima, apsorpcijom preko kože, i gutanjem, pri konzumiranju hrane, vode ili pušenju. 
Ako piralen dođe $\mathrm{u}$ dodir s kožom, to mesto treba odmah isprati $\mathrm{s}$ mnogo vode, $\mathrm{i}$ to je najefikasnije uraditi ispod slavine, a zatim oprati vodom i sapunom više puta. Odeća kontaminirana piralenom treba odmah da se skine i da se telo opere, kako je opisano. Odeća se odlaže na propisana mesta i pere. Osobe koje peru odeću treba da budu upozorene na opasna svojstva piralena, posebno na mogućnost resorpcije preko kože.

Vatrogasci koji gase požar na transformatorima $\mathrm{s}$ piralenom ne smeju $\mathrm{u}$ istom odelu i istim cipelama da odlaze van područja ugroženog požarom, kako ne bi došlo do dalje kontaminacije piralenom. Neposredno posle gašenja požara obavezno je detaljno pranje celog tela toplom vodom i sapunom (ne deterdžentom ni šamponom). Svi vatrogasci angažovani na gašenju požara na transformatorima s piralenom moraju da koriste zaštitna odela, rukavice, čizme i maske.

Piralen ima veliku sposobnost prodiranja kroz različite polimerne materijale koji se koriste i za izradu delova zaštitne opreme, pa pri izboru materijala za zaštitnu opremu vatrogasaca angažovanih na gašenju piralenskih požara o tome treba voditi računa.

U tabeli je prikazana otpornost različitih materijala na prodor piralena [4]:

Tabela

Vreme prodora piralena kroz različite materijale (debljina folije $2 \mathrm{~mm}$ )

\begin{tabular}{|c|l|c|}
\hline R. br. & \multicolumn{1}{|c|}{ Materijal } & $\begin{array}{c}\text { Vreme prodora } \\
\text { piralena }(\mathrm{h})\end{array}$ \\
\hline 1. & Butil guma & $>8$ \\
\hline 2. & Neopren guma & $>8$ \\
\hline 3. & Teflon plastika & $>8$ \\
\hline 4. & Viton guma & $>8$ \\
\hline 5. & Nitril guma & $1-4$ \\
\hline 6. & Prirodna guma $(*)$ & $<1$ \\
\hline 7. & Polietilen plastika $(*)$ & $<1$ \\
\hline
\end{tabular}

(*) ne preporučuje se zbog moguće razgradnje
Zaštitna odeća posle gašenja na transformatorima s piralenom mora da se dekontaminira pranjem vodom. Takođe, ona mora da se čuva od ulja i maziva, kako bi bila efikasna za zaštitu od piralena.

\section{Preventivne mere}

Zbog opasnosti od izlivanja polihlorovanih bifenila i njihovog prodora $u$ lanac ishrane, kao i opasnosti od produkata sagorevanja koji nastaju pri požarima ovih opasnih hemikalija, preventivne mere su od izuzetnog značaja. Da bi se rizik od posledica primene ove hemikalije sveo na minimum, neophodno je sprovesti sledeće mere bezbednosti:

- piralen mora biti skladišten prema uputstvu proizvođača i zahtevu o zaštiti daleko od oksidacionih sredstava, kao i od transformatora u eksploataciji koji sadrže piralen. To se posebno odnosi na prekidače i drugu opremu koja sadrži ovo opasno ulje. U slučaju ratnih opasnosti, bombardovanja ili bilo kojih neregularnih i nestabilnih stanja, transformatori i oprema koja sadrži piralen moraju biti isključeni, kako voltin luk ne bi upalio trafo-ulje i izazvao požar;

- transformatori s piralenom i sam piralen moraju biti zaštićeni od plamena požara, a piralen uskladišten u posebnoj prostoriji bez prisustva ikakvih drugih zapaljivih ili opasnih materijala;

- bezuslovno sprečavanje požara na transformatorima i piralenu imperativ je svakog preventivnog delovanja.

Ove mere zaštite neophodne su kako bi se eliminisali uzroci gorenja, izlivanja ili curenja piralena u okolnu sredinu. 


\section{Gašenje požara na transformato- rima i skladištima piralena}

O transformatorskim uljima pripadnici vatrogasnih jedinica nisu bili dovoljno obavešteni, jer su požari na piralenskim transformatorima bili izuzetno retki [4]. Takođe, o njima nisu mnogo znali ni stručnjaci koji se bave ekologijom. Postoje različita mišljenja o štetnosti transformatorskih ulja, ali se svi slažu da ona ostavljaju dugoročne posledice po živi svet. Korisnici ovih ulja, pak, ističu da su bezopasna i da spadaju u obična trafo-ulja, jer alternativno, a efikasno hlađenje bez ovih ulja nije moguće.

Za gašenje požara na postrojenjima koja sadrže piralen koriste se različita sredstva, a reagovanje na požar mora da bude brzo.

Mali požar na skladištima piralena lakše se neutrališe nego požar na transformatorima ili drugoj opremi koja sadrži ovo opasno ulje, a postoji i opasnost od visokog napona. Požar na buradima u kojima se skladišti piralen treba gasiti prahom, halonima (vrsta pene), ugljendioksidom, običnom srednjom ili teškom vazdušno-mehaničkom penom i raspršenom vodom. Ako je u pitanju požar na postrojenju pod visokim naponom, gašenje malih požara vrši se ugljendioksidom do nazivnog napona od 10000 volti, odnosno halonom i halogenim derivatima ugljovodonika do 100000 volti.

Veliki požar na piralenskim transformatorima ali i samog piralena, uspešno se može gasiti jedino halonima. Preko nazivnog napona od 100000 volti gašenje se mora obustaviti do isključenja transformatora sa napona. Po isključenju transformatora sa napona, za gašenje požara primenjuje se srednja vatrogasna pena. Dobre rezultate daje i fino raspršena voda, kao i vodena magla [4].
Zbog genotoksičnosti piralena i još veće opasnosti od produkata nastalih sagorevanjem ovog opasnog ulja, pri gašenju požara vatrogasci treba da deluju sa što veće udaljenosti, s kompletnom zaštitnom opremom, uvek iz smera duvanja vetra, s najmanjim mogućim brojem ljudi u zoni hemijske kontaminacije.

Pri gašenju požara vatrogasci ne treba da povećavaju zonu kontaminacije piralenom korišćenjem snažnih mlazeva vode, niti da dozvole da piralen prodire $u$ zemlju, vodu ili vazduh, naročito pri upotrebi pogrešnih sredstava za gašenje požara.

Požari na piralenu, nažalost, prouzrokuju žrtve u bliskoj i daljoj budućnosti, zavisno od količine akumuliranog piralena i oslobođenog genotoksina koji je nekontrolisano rasejan u životnoj sredini.

\section{Postupak s izlivenim piralenom}

Ukoliko dođe do isticanja piralena na tlo usled vanrednih okolnosti (požari na piralenskim transformatorima) ili iz oštećene ambalaže u kojoj je smešten (plastična burad), preduzimaju se mere čišćenja i sprečavanja prodiranja piralena i njegovih produkata u tlo [1].

Pri prosipanju manjih količina piralena na beton koristi se suv pesak ili drugi adsorbensi, kako bi se genotoksin upio. Pesak s upijenim piralenom pakuje se u plastične kese ili burad. Korišćeni alat, kontaminirana odeća i obuća dobro se zatvore $u$ tu istu burad. Pri velikom isticanju piralena na beton ili u uljnu jamu, neophodno je ograničiti razlivanje. Ako je spoljašnja temperatura manja od $10^{\circ} \mathrm{C}$, piralen će očvrsnuti i tada se može lako 
sakupiti. Pri većim spoljašnjim temperaturama (iznad $10^{\circ} \mathrm{C}$ ) mora da se obavi prepumpavanje pumpama u plastičnu burad ili vreće. Pri tom se za upijanje koristi pesak, kao i za mala isticanja.

Kada se dogode isticanja piralena u zemlju ili peščano tle, neophodno je da se: minaciju;

- angažuje stručno lice za dekonta-

- otpočne skidanje uljne mrlje od periferije ka centru, tako da se obuhvati i jedan deo nekontaminiranog tla, oko 50 $\mathrm{cm}$ od ivice mrlje;

- delovi kontaminiranog tla pakuju u plastičnu ambalažu, koju treba dobro zatvoriti;

- kontroliše kvalitet dekontaminacije tla preko ovlašćenih laboratorija;

- dekontaminacija ponavlja sve dok hemijske analize ne pokažu da piralen nije prisutan u zemlji;

- vreće i burad sa kontaminiranim materijalom uskladište na sigurno mesto, podlogu sa ilovačom.

Zbog svojih genotoksičnih karakteristika, ova ulja ne smeju da se prosipaju u okolinu ni pod kakvim uslovima.

\section{Zaključak}

Transformatorska ulja koriste se za hlađenje električnih transformatora, nerazgradiva su i spadaju u izuzetno opasne zagađivače čovekove okoline. Piralen, smeša hlorovanih bifenila s različitim sadržajem hlora, najčešće 54\%, sintetički je proizvod, izuzetno stabilan i nerazgradiv.
Rasuti piralen mora brzo i efikasno da se mehanički ukloni sa površine tla, kako ne bi prodro u zemljište i dospeo do podzemnih voda. Prodiranjem u tlo trajno zagađuje zemljište i podzemne vode.

Jedini efikasan način uklanjanja ovog ulja vrši se termičkom razgradnjom, odnosno precizno vođenim postupkom sagorevanja, kako ni jedan opasan produkat sagorevanja ne bi izašao $u$ spoljnu sredinu.

Sagorevanjem piralena na otvorenom prostoru oslobađa se veliki broj otrovnih i kancerogenih produkata. Gašenje požara na piralenu rizično je, jer postoji opasnost od trovanja i zagađenja okoline.

Požari na piralenskim transformatorima izuzetno su opasni, kako po vatrogasce, tako i po okolno stanovništvo, zbog oslobađanja velike količine opasnih produkata koji nastaju sagorevanjem piralena.

Piralen spada u genotoksične i kancerogene supstance s produženim vremenom delovanja, pa je njegova upotreba trajno zabranjena u zemljama Evropske unije.

Literatura:

[1] Sovrlić, M.; Stevanović-Čarapina, H.: Komercijalna upotreba polihlorovanih bifenila i moguće zagađenje životne sredine, Elektroprivreda, br.2, Beograd, 2002, 63-71.

[2] Jovičić, Z.: Opasne materije, Institut za kvalitet radne i životne sredine 1 maj, Niš, 1996.

[3] Anđelković-Lukić, M.: Produkti detonacije i sagorevanja eksplozivnih i drugih materija izazvanih NATO bombardovanjem SRJ - ekološko razmatranje, Kumulativna naučno-tehnička informacija br.11, Vojnotehnički institut, Beograd 2004.

[4] Karabasil, D. i dr.: Gašenje požara na transformatorima sa piralenom, Zbornik radova -7 . jugoslovensko 4 . međunarodno savetovanje zaštite od požara i eksplozije, Novi Sad 2000, 268-276. 